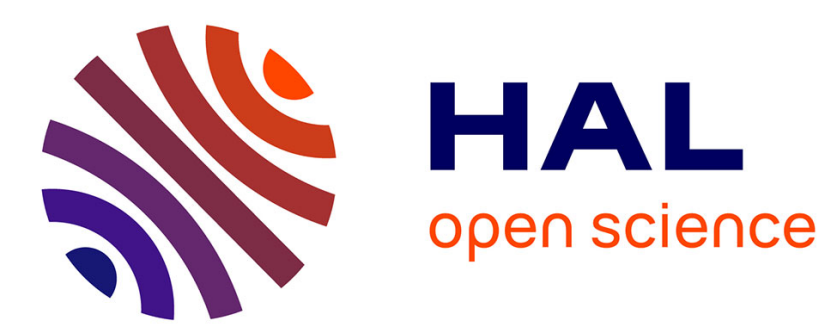

\title{
Thermal ageing of a silane-crosslinked polyethylene stabilised with a thiodipropionate antioxidant
}

\author{
Anne Xu, Sébastien Roland, Xavier Colin
}

\section{To cite this version:}

Anne Xu, Sébastien Roland, Xavier Colin. Thermal ageing of a silane-crosslinked polyethylene stabilised with a thiodipropionate antioxidant. Polymer Degradation and Stability, 2020, 181, pp.109276. 10.1016/j.polymdegradstab.2020.109276 . hal-02931932

\section{HAL Id: hal-02931932 \\ https://hal.science/hal-02931932}

Submitted on 7 Sep 2020

HAL is a multi-disciplinary open access archive for the deposit and dissemination of scientific research documents, whether they are published or not. The documents may come from teaching and research institutions in France or abroad, or from public or private research centers.
L'archive ouverte pluridisciplinaire HAL, est destinée au dépôt et à la diffusion de documents scientifiques de niveau recherche, publiés ou non, émanant des établissements d'enseignement et de recherche français ou étrangers, des laboratoires publics ou privés. 


\title{
Thermal ageing of a silane-crosslinked polyethylene stabilised with a thiodipropionate antioxidant
}

\author{
Anne Xu, Sébastien Roland, Xavier Colin * \\ PIMM, Arts et Métiers Institute of Technology, CNRS, CNAM, HESAM University, 151 Boulevard de L'Hôpital, Paris, 75013, France
}

Keywords:

Silane-crosslinked polyethylene

Thermal ageing

Stabilisation

Thiodipropionate antioxidant

Physical loss

Chemical consumption

Activation energy

\begin{abstract}
A B S T R A C T
The thermal ageing of a silane-crosslinked polyethylene stabilised with 1 wt\% of distearyl thiodipropionate (Irganox PS802) was studied in air at three different temperatures: $87^{\circ} \mathrm{C}, 110^{\circ} \mathrm{C}$, and $130{ }^{\circ} \mathrm{C}$. FTIR spectroscopy and DSC under $\mathrm{O}_{2}$ were used in a complementary way to monitor the antioxidant (AO) depletion during thermal ageing, but also to detect the polymer oxidation. In particular, at the three ageing temperatures under study, it was observed that the physical loss of AO is the main ageing mechanism and is controlled by AO evaporation. However, the contribution of the AO chemical consumption in the overall kinetics of AO depletion was also estimated. In addition, the temperature dependences of the evaporation constant and the rate constant of the chemical consumption of AO were approximated with the usual Arrhenius law in the temperature range under investigation. Although the corresponding activation energies must be considered with caution, due to the limited amount of data acquired in this study, they were found to be in good agreement with the few results available in the literature.
\end{abstract}

\section{Introduction}

Crosslinked polyethylene (XLPE) is widely used as insulation for electrical power cables in particular in nuclear power plant (NPP) where about 25000 cables for a total length of about $1500 \mathrm{~km}$ are installed inside each NPP unit [1,2]. Cables play a key role in NPP operation as they ensure the transmission of electrical signals. For such applications, cables need to endure high temperature variations and high irradiation doses. Under normal service conditions, the average temperature is estimated at around $40-50{ }^{\circ} \mathrm{C}$. However, under accidental conditions, for instance during a Loss of Coolant Accident (LOCA), which is one of the most severe accidental scenarios, the maximum temperature can reach $150^{\circ} \mathrm{C}$ [3]. Hence, it is crucial to understand and monitor the degradation of electrical cables under normal and accidental conditions in order to ensure the NPP safe operations, keeping in mind that the polymeric insulation is the most sensitive (an thus, the weakest) component.

Oxidative degradation can occur at all the stages of the polymer lifecycle, from its production to its in-service use, resulting on irreversible modifications of the polymer chemical composition. In

\footnotetext{
* Corresponding author.

E-mail address: xavier.colin@ensam.eu (X. Colin).
}

order to protect it against oxidation, a low concentration of antioxidants $(\mathrm{AO})$ is generally incorporated into the polymer during the first steps of the processing operation. Different types of AO exist and mainly differ by their general chemical structure and their stabilisation mechanism. The two main types of AO are free radicals scavengers (e.g. hindered phenols and secondary aromatic amines) and hydroperoxides decomposers (e.g. organic phosphites and sulphides) [4-6]. The first ones are also called "primary antioxidants" or "chain breaking antioxidants" as they increase the termination rate by reacting with peroxy radicals formed during the first propagation step, thus efficiently interrupting the radical chain propagation. In contrast, the second ones are called "secondary antioxidants" or "preventive antioxidants" as they reduce the initiation rate by converting hydroperoxides into non-radical products, thus efficiently retarding the auto-accelerated character of thermal oxidation.

Among preventive antioxidants, thiodipropionates, and in particular distearyl thiodipropionate (also called DSTDP or Irganox PS802), have long been known to be effective in polyolefins at high temperature during processing as they contain a thioether function (noted -S- for a sake of simplicity) capable of reducing hydroperoxides into alcohols, as shown in Fig. 1 [7-10].

Thus, AO stabilise polymers by competing with the most harmful steps of the close-loop mechanistic scheme. Their 


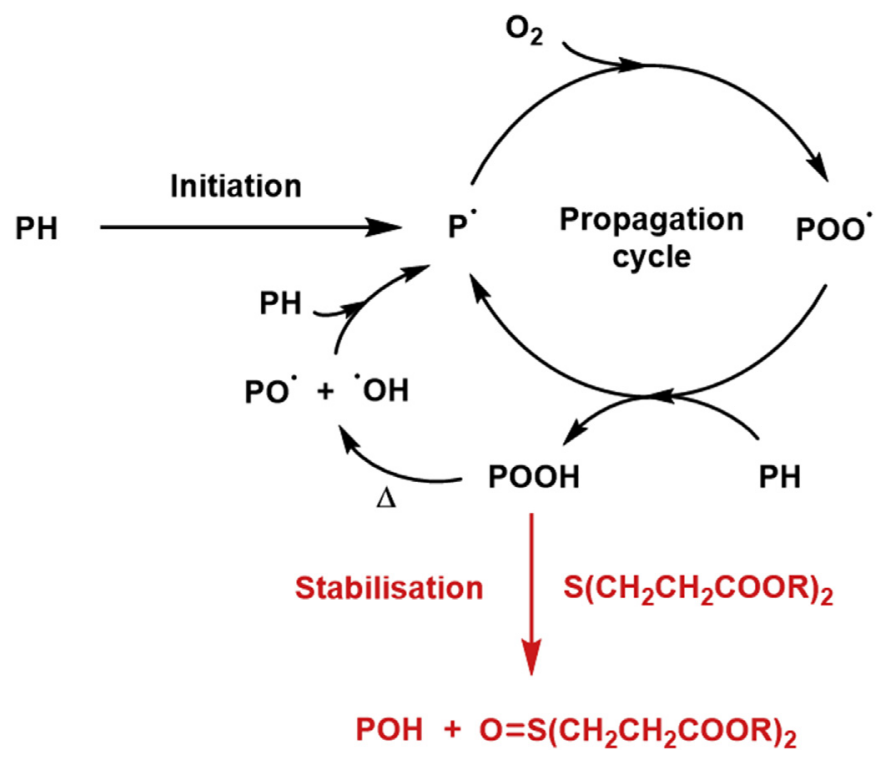

Fig. 1. Simplified mechanistic scheme for radio-thermal oxidation of a polyolefin stabilised by a thiodipropionate antioxidant [9-11].

efficiency seems essentially due to the specific chemical functions that they contain. However, another important condition necessary for AO efficiency is to reduce their physical loss, as it is paramount to maintain a sufficient $\mathrm{AO}$ concentration in the polymer matrix during all the stages of the polymer lifecycle. Indeed, during the thermal ageing of the stabilised material, AO can be consumed by the stabilisation reactions, but can also leave the polymer. Several parameters affect the physical loss of $\mathrm{AO}$, such as its solubility into the polymer matrix, its volatility and its diffusivity [10,12-14]. Physical loss of AO can occur by diffusion with $\mathrm{AO}$ exudation at the sample surface [15], and/or by evaporation [16]. In linear PE, the chemical consumption of the thiodipropionate antioxidant under investigation would not be the predominant mechanism. Indeed, according to Richaud et al. [16], its concentration would deplete and vanish mainly through physical loss.

This study aims at elucidating the AO behaviour during the thermal ageing in air at three different temperatures $\left(87^{\circ} \mathrm{C}, 110^{\circ} \mathrm{C}\right.$, and $130^{\circ} \mathrm{C}$ ) of a silane-crosslinked polyethylene (Si-XLPE) stabilised with $1 \mathrm{wt} \%$ of DSTDP. Two complementary physico-chemical characterization techniques, Fourier-transformed infrared (FTIR) spectroscopy and differential scanning calorimetry (DSC) under $\mathrm{O}_{2}$, were used to monitor the AO depletion during thermal ageing and to assess the respective contributions of the chemical consumption and physical loss. The results thus obtained are compared with the few data available in the literature to be criticized.

\section{Materials and methods}

\subsection{Films of silane-crosslinked PE stabilised with DSTDP}

Films of silane-crosslinked polyethylene (Si-XLPE) of about $500 \mu \mathrm{m}$ thick containing $1 \mathrm{wt} \%$ of DSTDP were directly provided by Nexans. These films were produced by extrusion of a linear lowdensity polyethylene grafted with vinyl tri-methoxy silane side groups (Si-g-LLDPE) which was supplied by SABIC under the commercial reference PE $318 \mathrm{CNJ}$. The crosslinking was then performed by immersion in water at $65{ }^{\circ} \mathrm{C}$ for $48 \mathrm{~h}$ [17]. The density and gel content of the resulting Si-XLPE are about $0.918 \mathrm{~g} \mathrm{~cm}^{-3}$ and $71 \%$, respectively.
After these processing operations, the films were stored at ambient temperature in a desiccator containing silica gel before any physico-chemical characterization.

In addition, films of about $100 \mu \mathrm{m}$ thick of Si-g-LLDPE with concentrations of DSTDP ranging from $0 \mathrm{wt} \%$ to $1.5 \mathrm{wt} \%$ were produced by compression moulding at $150{ }^{\circ} \mathrm{C}$ for $4 \mathrm{~min}$, i.e. according to the same experimental protocol described in a previous article [18]. The DSTDP powder used to prepare these films was supplied by Sigma Aldrich. The chemical structure of the AO under investigation is given in Fig. 2. These uncrosslinked samples were used to establish the calibration curves necessary to perform any quantitative study of the AO depletion, but also to plot the corresponding kinetic curves.

A Differential scanning calorimetry (DSC) analysis was performed on the AO powder. The DSC thermogram (restricted to the temperature range around the melting point of $\mathrm{AO}$ ) is given in Fig. 3. According to this analysis, the melting point and enthalpy of DSTDP are about $67 \pm 1{ }^{\circ} \mathrm{C}$ and $208 \pm 1 \mathrm{~J} \mathrm{~g}^{-1}$, respectively.

Additional information reported in literature for this AO [19] is also compiled in Table 1 . Thermal stability $\mathrm{T}_{\mathrm{x}}$ wt\% under air corresponds to the temperature at which is observed a mass loss of $x \mathrm{wt}$ $\%$.

\subsection{Thermal ageing conditions}

Thermal ageing was performed under air, in air-ventilated ovens, at three different temperatures: $87{ }^{\circ} \mathrm{C}, 110{ }^{\circ} \mathrm{C}$, and $130{ }^{\circ} \mathrm{C}$. A Si-XLPE film without any additional thiodipropionate antioxidant (i.e. 0 wt\% of DSTDP) was also aged under the same exposure conditions as control sample. It should be mentioned that this sample contains a very small amount (about $0.1 \mathrm{wt} \%$ ) of storage antioxidants, mainly BHT and Irganox 1076 [18].

\subsection{Fourier-transform infrared spectroscopy}

FTIR spectra were recorded in transmission mode using a Perkin Elmer FTIR Frontier spectrometer, after averaging the 16 scans obtained with a resolution of $4 \mathrm{~cm}^{-1}$. For each sample, at least three FTIR measurements were performed. This analytical technique enables to detect and monitor the chemical changes occurring in the material during thermal ageing. In particular, it was used to monitor the AO depletion and to detect the formation of oxidation products.

\subsection{Differential scanning calorimetry under $\mathrm{O}_{2}$ (OIT measurements)}

OIT measurements were performed under a pure $\mathrm{O}_{2}$ flow at $195{ }^{\circ} \mathrm{C}$ using a TA Instrument DSC Q10 calorimeter. This temperature was chosen in order to have an acceptable duration of experiments for unaged and aged samples. Samples with a mass ranged between $5 \mathrm{mg}$ and $7 \mathrm{mg}$ were introduced in opened standard aluminium pans. These samples were first heated, under pure $\mathrm{N}_{2}$ flow of $50 \mathrm{~mL} \mathrm{~min}{ }^{-1}$, from room temperature to $195^{\circ} \mathrm{C}$ at a heating rate of $10^{\circ} \mathrm{C} \cdot \mathrm{min}^{-1}$. After an isotherm segment of 5 min under $\mathrm{N}_{2}$, the gas supply was switched from $\mathrm{N}_{2}$ to $\mathrm{O}_{2}$ while maintaining the

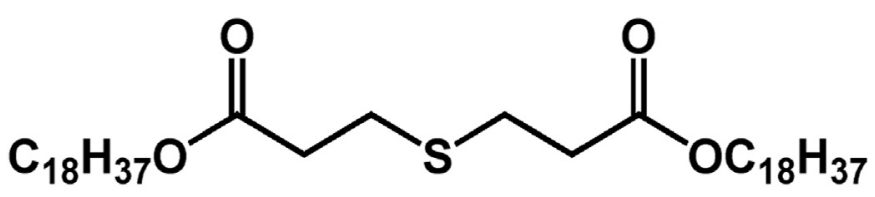

Fig. 2. Chemical structure of DSTDP. 


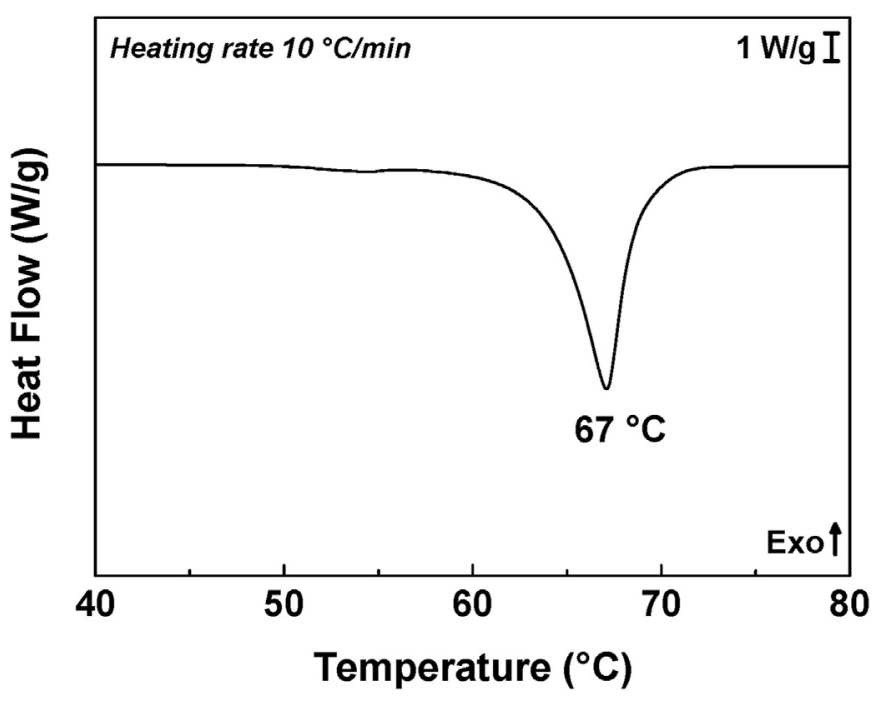

Fig. 3. DSC thermogram of DSTDP powder obtained with a heating rate of $10{ }^{\circ} \mathrm{C} \cdot \mathrm{min}^{-1}$ under nitrogen flow.

Table 1

Physico-chemical characteristics of DSTSP.

\begin{tabular}{lll}
\hline Properties & Value & Reference \\
\hline Molar mass $\left(\mathrm{g} \cdot \mathrm{mol}^{-1}\right)$ & 683 & {$[19]$} \\
Melting point $\left({ }^{\circ} \mathrm{C}\right)$ & $67 \pm 1$ & This study \\
Melting enthalpy $\left(\mathrm{J.g}^{-1}\right)$ & $208 \pm 1$ & This study \\
Density at $20{ }^{\circ} \mathrm{C}\left(\mathrm{g} \mathrm{cm}^{-3}\right)$ & 0.98 & {$[19]$} \\
Thermal stability: & & \\
$\mathrm{T}_{5} \mathrm{wt} \%\left({ }^{\circ} \mathrm{C}\right)$ & 270 & {$[19]$} \\
$\mathrm{T}_{10} \mathrm{wt} \%\left({ }^{\circ} \mathrm{C}\right)$ & 320 & {$[19]$} \\
$\mathrm{T}_{50 \mathrm{wt} \%}\left({ }^{\circ} \mathrm{C}\right)$ & 342 & {$[19]$} \\
\hline
\end{tabular}

same gas flow ( $\left.50 \mathrm{~mL} \mathrm{~min}{ }^{-1}\right)$ in order to access the oxidation induction time (OIT) at $195^{\circ} \mathrm{C}$. For each sample, at least three measurements were performed. OIT was then determined with the tangent method, corresponding to the duration between the introduction of $\mathrm{O}_{2}$ flow in the DSC cavity and the onset of the oxidation exotherm. This technique enables to measure the oxidation induction time (OIT) at a given temperature which, in the case of stabilised polymers, gives an assessment of the antioxidant concentration [16]. In particular, in the case of DSTDP, as the stabilizing function is the sulphide, OIT measurements give an estimation of the concentration of sulphides.

\subsection{Differential scanning calorimetry under $\mathrm{N}_{2}$ (DSC measurements)}

DSC analysis was also used to detect the changes in crystalline morphology of Si-XLPE during its thermal ageing. DSC thermograms were recorded with a TA instrument DSC Q1000 calorimeter beforehand calibrated with an indium reference. Samples with a mass ranged between 5 and $8 \mathrm{mg}$ were introduced in a closed standard aluminium pan to be analysed between - $50{ }^{\circ} \mathrm{C}$ and $250{ }^{\circ} \mathrm{C}$, with heating and cooling rates of $10^{\circ} \mathrm{C} \cdot \mathrm{min}^{-1}$ under a pure $\mathrm{N}_{2}$ flow of $50 \mathrm{~mL} \mathrm{~min}^{-1}$. As for other techniques, for each sample, at least three measurements were performed. The global crystallinity ratio $\left(\chi_{c}\right)$ of the polymer was determined from the area under the endothermic peak in the DSC thermogram, using the common equation:

$$
\chi_{c}=\frac{\Delta H_{m}}{\Delta H_{m, \infty}}
$$

where $\Delta \mathrm{H}_{\mathrm{m}}$ and $\Delta \mathrm{H}_{m, \infty}$ are the melting enthalpies (J.g $\left.{ }^{-1}\right)$ of the sample under investigation and the PE crystal, respectively. In literature, the commonly used value for $\Delta \mathrm{H}_{m, \infty}$ is $290 \mathrm{~J} \mathrm{~g}^{-1}[20,21]$.

The initial DSC thermogram of the stabilised Si-XLPE film is given in Fig. 4. The melting point and enthalpy of Si-XLPE are about $114 \pm 1^{\circ} \mathrm{C}$ and $119 \pm 1 \mathrm{Jg}^{-1}$, respectively. The crystallinity ratio of SiXLPE calculated with Eq. (1) is about $41 \pm 1 \%$. A small endothermic peak corresponding to the melting of DSTDP crystals was also detected at $66^{\circ} \mathrm{C}$. As explained in the previous study [18], knowing the melting enthalpy of the commercially available crystalline structure of AO, i.e. the DSTDP powder (see Table 1), it was possible to estimate the concentration of insoluble AO in the Si-XLPE matrix, using the following equation:

$[A O]_{\text {insol }}=\frac{\Delta H_{m, A O, \text { film }}}{\Delta H_{m, \text { pure } A O}} \times \rho_{P E}$

where $\rho_{\mathrm{PE}}$ is the polymer density $\left(0.918 \mathrm{~g} \mathrm{~cm}^{-3}\right), \Delta \mathrm{H}_{\mathrm{m} . \mathrm{AO} \text {.film }}$ the melting enthalpy of AO crystals in the Si-XLPE film under study $\left(\mathrm{J} . \mathrm{g}^{-1}\right)$ and $\Delta \mathrm{H}_{\mathrm{m}}$, pure Ao the melting enthalpy of the pure AO crystal $\left(142 \mathrm{~kJ} \mathrm{~mol}^{-1}\right)$.

Using Eq (2), it is found that the Si-XLPE film stabilised by a total concentration of about $(1.3 \pm 0.1) \times 10^{-2} \mathrm{~mol} \mathrm{~L}^{-1}(\sim 1 \mathrm{wt} \%)$ of DSTDP antioxidant contains about $(1.5 \pm 0.4) \times 10^{-3} \mathrm{~mol} \mathrm{~L}^{-1}$ (i.e. $\sim 0.1 \mathrm{wt} \%$ ) of insoluble DSTDP. In a previous study [18], a threshold concentration equal to $0.9 \mathrm{wt} \%$, above which crystals of AO start to be detected, was found for Si-XLPE stabilised with a phenolic antioxidant (Irganox 1076). Such a concentration, which can be related to the solubility limit of AO into the Si-XLPE matrix, seems to be detected here also for DSTDP. It can thus concluded that the Si-XLPE film under study, containing $1 \mathrm{wt} \%$ of DSTDP antioxidant, is fully saturated in $\mathrm{AO}$, with only $0.1 \mathrm{wt} \%$ of insoluble AO.

\section{Results and discussion}

\subsection{Establishment of the calibration curves}

Calibration curves for FTIR spectroscopy and OIT measurements were established using stabilised Si-g-LLDPE films containing an increasing concentration of DSTDP.

Using FTIR spectroscopy, the IR absorption band of the ester function of AO can clearly be seen at $1740 \mathrm{~cm}^{-1}$ (Fig. 5a). The normalised absorbance of the IR band at $1740 \mathrm{~cm}^{-1}$ was plotted against the concentration of ester functions in Fig. 5b. In this concentration range, the material under study seems to obey the Beer-Lambert's law, which can be written as follows:

$A=\varepsilon \times e \times C$

where $A$ is the absorbance, e the sample thickness $(\mathrm{cm}), C$ the concentration of the absorbing species $\left(\mathrm{mol}^{-1} \mathrm{~L}^{-1}\right.$ ) and $\varepsilon$ the molar extinction coefficient (L.mol $\left.{ }^{-1} \cdot \mathrm{cm}^{-1}\right)$.

The molar extinction coefficient estimated with the slope of the curve is about $550 \pm 10 \mathrm{~L} \mathrm{~mol} \mathrm{~cm}^{-1}$ for the ester function, which is quite concordant with literature data [16].

According to literature, OIT can give an assessment of the antioxidant concentration in stabilised polymers [16,22-24]. Hence, similarly to FTIR spectroscopy, OIT experiments were performed on Si-g-LLDPE films stabilised with an increasing concentration of $\mathrm{AO}$ in order to obtain the calibration curve shown in Fig. 6. 

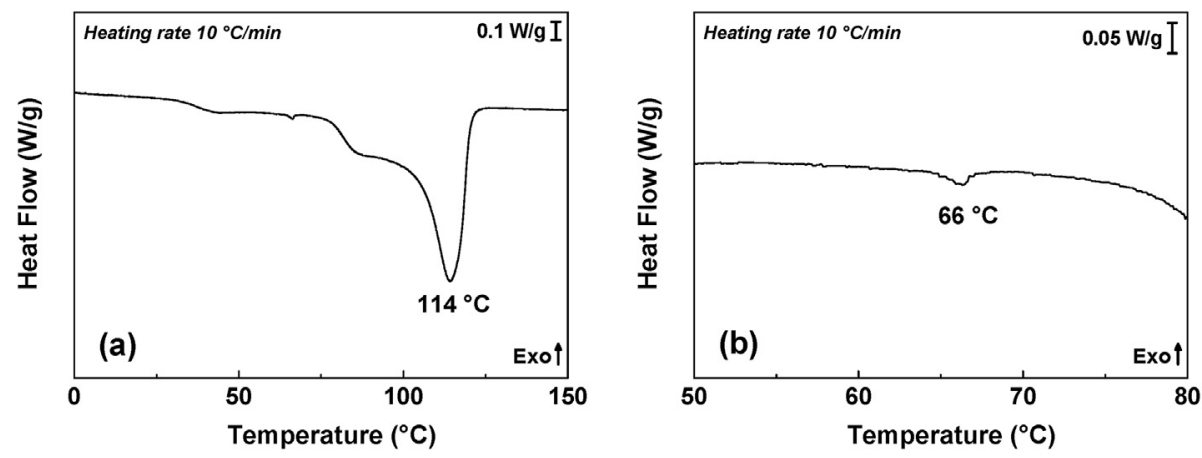

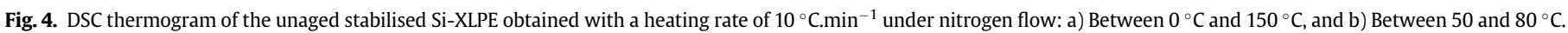
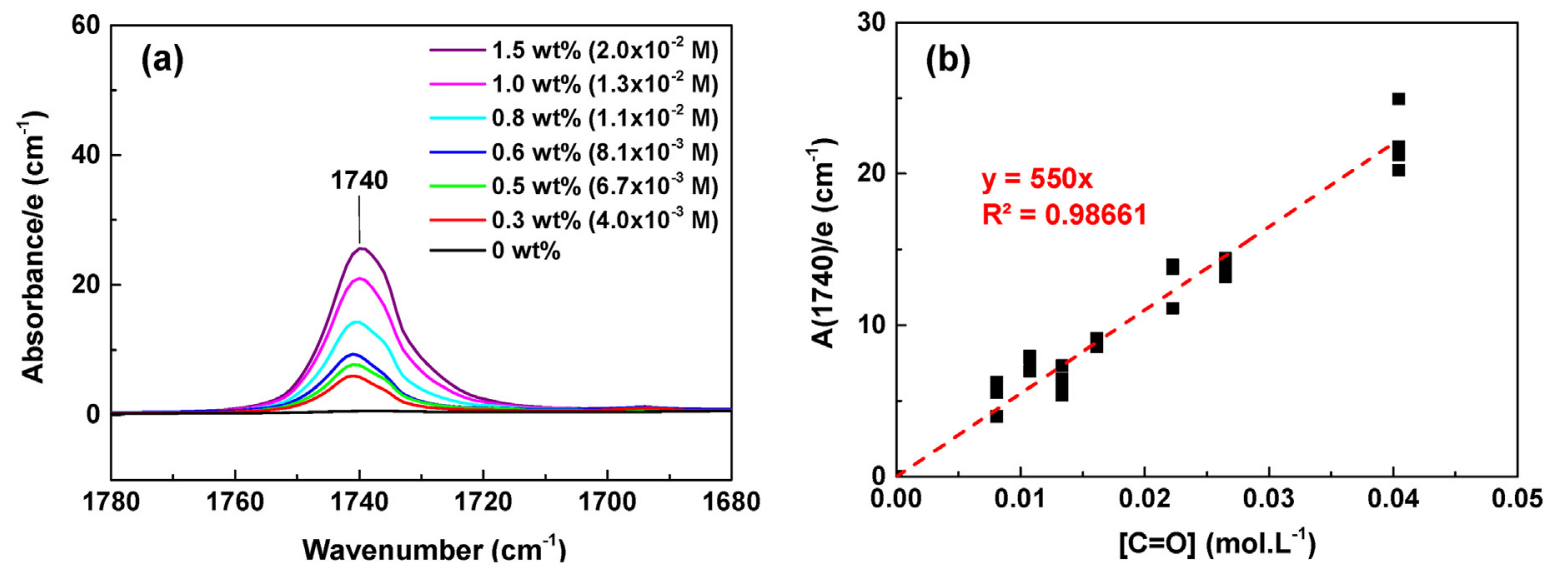

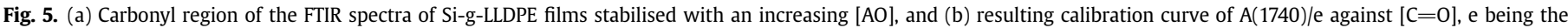
sample thickness.

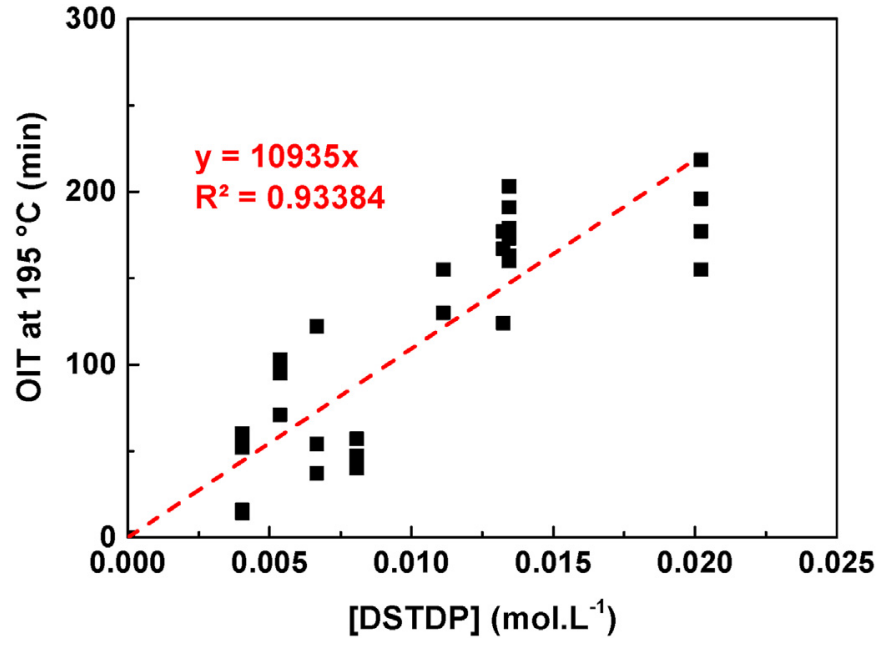

Fig. 6. Calibration curve of $\mathrm{OIT}_{195^{\circ} \mathrm{C}}$ against [DSTDP].

The scattering of OIT data seems to be relatively important. A first hypothesis to explain this large scattering could be a poor dispersion and dissolution, i.e. a heterogeneous distribution, of AO molecules in the Si-g-LLDPE matrix. Indeed, OIT experiments are performed on small pieces of samples. As OIT experiments were performed at least three times on different parts of the sample, a heterogeneity of AO distribution could induce such a scattering of OIT values. However, FTIR spectroscopy rather pleads in favour of a good dissolution of the DSTDP antioxidant into the Si-g-LLDPE matrix (Fig. 5b), contrary to what could have been observed for a phenolic antioxidant (Irganox 1076) in a previous study [18].

A second hypothesis could be that OIT measurements would not be ideal for characterizing the stabilizing efficiency of this type antioxidant. In fact, in the literature, a good correlation is generally found between OIT values and antioxidant concentrations for hindered phenols. However, in the case of a secondary AO such as DSTDP, it appeared that OIT measurements can show some limitations $[9,23,25]$. Indeed, the OIT calibration curve obtained by Richaud et al. [16] for DSTDP in a HDPE matrix also showed an nonnegligible scattering of data.

Finally, beyond a critical concentration of about $1.3 \times 10^{-2} \mathrm{~mol} \mathrm{~L}^{-1}$ (i.e. $1 \mathrm{wt} \%$ ) of DSTDP antioxidant in the Si-gLLDPE matrix, a saturation plateau seems to appear on the calibration curve in Fig. 5b. As already explained in previous section, this slope reduction is due to the formation of an insoluble AO phase in the Si-g-LLDPE matrix. In other words, beyond $1 \mathrm{wt} \%$ of DSTDP, the Si-g-LLDPE film is fully saturated in AO and thus, AO crystals begin to appear in the Si-g-LLDPE matrix.

\subsection{Physico-chemical characterization of the stabilised Si-XLPE during thermal ageing}

Fig. 7 shows the carbonyl region of the FTIR spectra obtained during the thermal ageing of the stabilised Si-XLPE at the three temperatures under study. At these temperatures, a continuous decrease of the IR absorption band of the ester function (at $1741 \mathrm{~cm}^{-1}$ ) of AO is observed. Then, as the thermal ageing proceeds, 

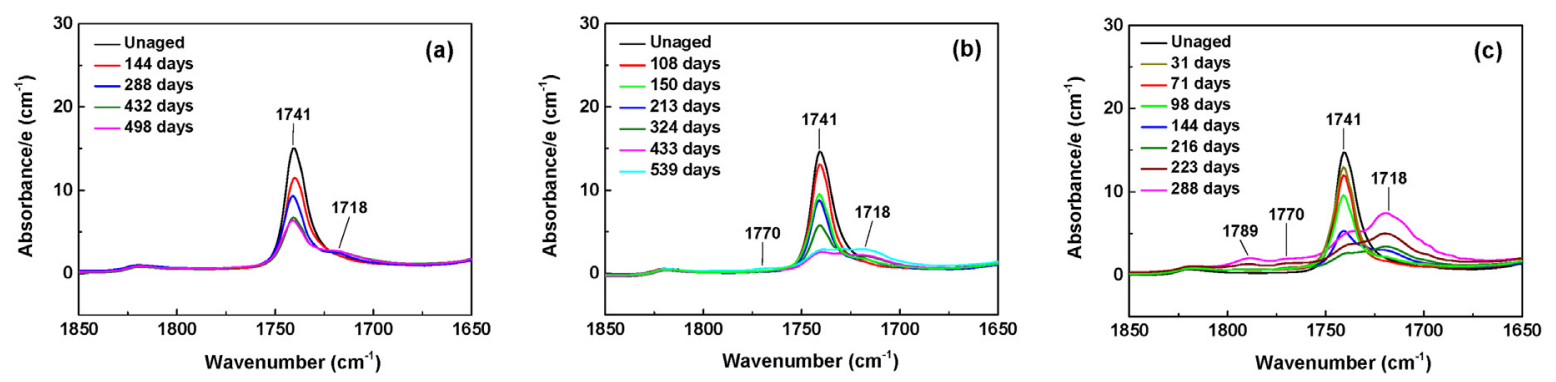

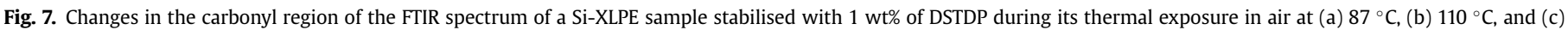
$130{ }^{\circ} \mathrm{C}$.

new IR bands appear around $1718 \mathrm{~cm}^{-1}, 1738 \mathrm{~cm}^{-1}, 1770 \mathrm{~cm}^{-1}$, and $1790 \mathrm{~cm}^{-1}$. These latter were assigned to oxidation products of the polymer, as they were also observed during the thermal ageing of the pure Si-XLPE. Similarly, OIT is also continuously decreasing with ageing time at these three temperatures, as shown in Table 2.

Fig. 8 shows the DSC thermograms obtained during the thermal ageing of the stabilised Si-XLPE film at the three temperatures under study. A modification in the general shape of the melting peak of the polymer can be observed for all three temperatures. When the temperature of exposure is located within the melting range of the polymer (i.e. at $87{ }^{\circ} \mathrm{C}$ and $110{ }^{\circ} \mathrm{C}$ ), only part of the crystals are melted during the thermal exposure and a partial recrystallization operates during the cooling at room temperature before DSC analysis. The new crystals are characterized by a slightly higher melting point on the DSC thermograms, i.e. they are thicker and more perfect than the initial crystals. On the contrary, when the temperature of exposure is above the melting point of the polymer (i.e. at $130{ }^{\circ} \mathrm{C}$ ), all polymer crystals are melted during the thermal exposure and thus, a total recrystallization operates during the cooling at room temperature before DSC analysis. However, there is no significant change in crystallinity ratio during thermal ageing, as shown in Fig. 9 . At $130^{\circ} \mathrm{C}$, a very slight decrease in crystallinity can be noted (from $41 \pm 1 \%$ initially, up to $37 \pm 1 \%$ after 30 days of exposure) presumably due to polymer post-crosslinking in molten state. However, at lower temperature (i.e. at $87^{\circ} \mathrm{C}$ and $110^{\circ} \mathrm{C}$ ), the fraction of molten polymer being limited, this process of crystallization hindrance is no longer detectable. It can be thus concluded that, for all the three temperatures under investigation, there is no effect (or a negligible effect) of oxidation on the polymer crystallinity.

Using the previously determined calibration curves (Figs. 5b and 6), the concentrations of active functions (sulphides) and esters of AO were estimated. The concentration of ketones coming from polymer oxidation (absorption band around $1718 \mathrm{~cm}^{-1}$ on FTIR spectra) was also estimated using the Beer-Lambert's law with a molar extinction coefficient of $300 \mathrm{~L} \mathrm{~mol}^{-1} \mathrm{~cm}^{-1}[16,26]$. These concentrations were plotted versus ageing time, for all the three temperatures under investigation, as shown in Fig. 10. It can be observed that both sulphides and ester functions of AO deplete with ageing time. However, it is noteworthy that, when OIT becomes relatively low $\left(<20 \mathrm{~min}\right.$ at $\left.195^{\circ} \mathrm{C}\right)$, ketones coming from polymer oxidation start to be detected by FTIR spectroscopy and their concentration immediately increases. This is particularly significant for the highest ageing temperature under study $\left(130^{\circ} \mathrm{C}\right)$. As for linear PE [30], the thermal oxidation of pure Si-XLPE leads to the formation of a wide variety of carbonyl products which can be, in a first approach, separated into two groups: on one side, carboxylic acids and ketones of which the IR absorption bands are typically ranged between 1700 and $1720 \mathrm{~cm}^{-1}$, and on the other side, aldehydes and esters for which they are rather located between 1733 and $1741 \mathrm{~cm}^{-1}$. The contribution of these two latter is hence added to the contribution of esters from AO in the IR absorption band at $1740 \mathrm{~cm}^{-1}$, thus explaining why the global apparent concentration of esters reaches a final value which is a quite high compared to the concentration of sulphides and the value of OIT (as shown in Fig. 10).

At this final stage, and for the three temperatures under investigation, OIT is not zero (see Table 2) and the concentration of oxidation products is still relatively low (typically about $10^{-3}$ $10^{-2} \mathrm{~mol} \mathrm{~L}^{-1}$ ). In addition, as mentioned before, no significant modification of the polymer crystallinity (using DSC under $\mathrm{N}_{2}$ ) was detected, contrarily to unstabilised Si-XLPE. Thus, these results suggest that the polymer oxidation is starting although few AO are still present in the material, which seems to indicate a heterogeneous oxidation of the polymer matrix.

\subsection{Kinetic study of the antioxidant consumption during thermal ageing}

The AO depletion can be expressed as the contribution of the AO physical loss and chemical consumption. According to Calvert and Billingham [27], in the case of sufficiently thin polymer films, the physical loss is only due to evaporation, of which the corresponding rate is proportional to AO concentration. Concerning the chemical

Table 2

OIT values measured at $195^{\circ} \mathrm{C}$ during the thermal ageing of stabilised Si-XLPE in air at $87^{\circ} \mathrm{C}, 110^{\circ} \mathrm{C}$, and $130{ }^{\circ} \mathrm{C}$.

\begin{tabular}{|c|c|c|c|c|c|}
\hline \multicolumn{2}{|l|}{$\mathrm{T}=87^{\circ} \mathrm{C}$} & \multicolumn{2}{|l|}{$\mathrm{T}=110^{\circ} \mathrm{C}$} & \multicolumn{2}{|l|}{$\mathrm{T}=130^{\circ} \mathrm{C}$} \\
\hline Ageing time (days) & $\mathrm{OIT}_{195^{\circ} \mathrm{C}}(\mathrm{min})$ & Ageing time (days) & $\mathrm{OIT}_{195^{\circ} \mathrm{C}}(\mathrm{min})$ & Ageing time (days) & $\mathrm{OIT}_{195^{\circ} \mathrm{C}}(\mathrm{min})$ \\
\hline 0 & $179 \pm 22$ & 0 & $179 \pm 22$ & 0 & $179 \pm 22$ \\
\hline 144 & $109 \pm 18$ & 108 & $92 \pm 3$ & 31 & $68 \pm 10$ \\
\hline 288 & $36 \pm 12$ & 150 & $40 \pm 6$ & 71 & $54 \pm 11$ \\
\hline 432 & $15 \pm 2$ & 213 & $21 \pm 1$ & 98 & $43 \pm 4$ \\
\hline 498 & $12 \pm 1$ & 324 & $17 \pm 2$ & 144 & $21 \pm 1$ \\
\hline- & - & 433 & $4 \pm 1$ & 216 & $6 \pm 1$ \\
\hline- & - & 539 & $2 \pm 1$ & 288 & $2 \pm 1$ \\
\hline
\end{tabular}



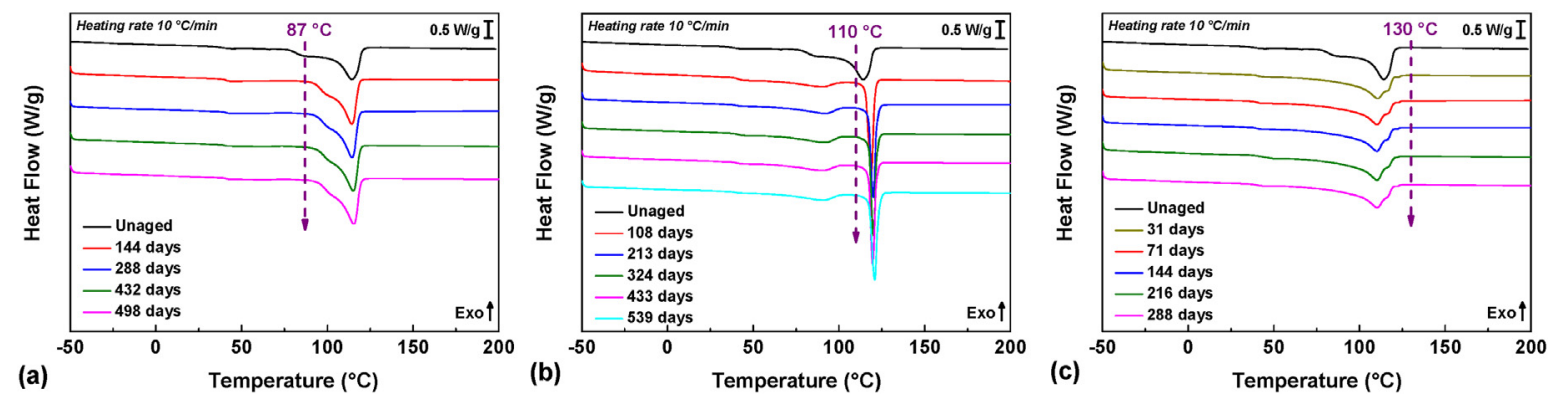

Fig. 8. Changes in the DSC thermograms of a Si-XLPE sample stabilised with 1 wt $\%$ of DSTDP during its thermal exposure in air at (a) $87{ }^{\circ} \mathrm{C}$, (b) $110{ }^{\circ} \mathrm{C}$, and (c) $130{ }^{\circ} \mathrm{C}$.

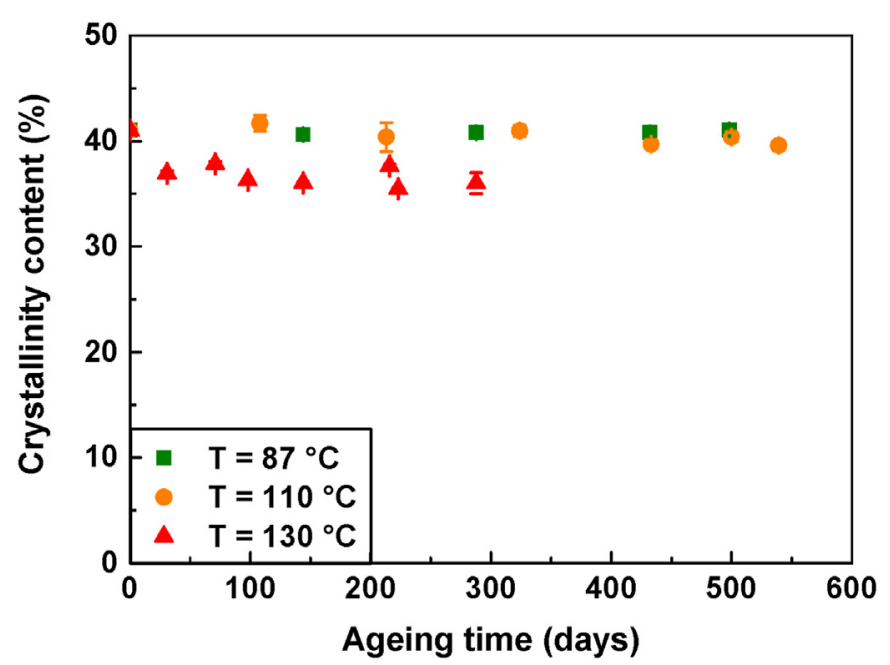

Fig. 9. Changes in the crystallinity ratio of Si-XLPE sample stabilised with $1 \mathrm{wt} \%$ of DSTDP during its thermal exposure in air at: $87^{\circ} \mathrm{C}(\boldsymbol{\square}), 110^{\circ} \mathrm{C}(\boldsymbol{\bullet})$, and $130{ }^{\circ} \mathrm{C}(\boldsymbol{\Delta})$.

consumption, the main acting mechanism can be summarized by the single bimolecular reaction:

$A O+P O O H \rightarrow$ Inactive products $\left(k_{d}\right)$

The resulting balance equation is:

$\frac{d[A O]}{d t}=-K[A O]-k_{d}[A O][P O O H]$

where $\mathrm{K}$ is the evaporation constant and $\mathrm{k}_{\mathrm{d}}$ the rate constant of the chemical consumption of AO.

As shown in Appendix A, Eq. (5) can be transformed in a more adequate form, which can be integrated with respect to time provided that the hydroperoxide concentration does not vary much and remains almost equal to its initial value $[\mathrm{POOH}]_{0}$ (i.e. at low conversion ratios). It finally comes:

$$
[A O]=[A O]_{0} \exp \left[-\left(\mathrm{K}+k_{d}[P O O H]\right) t\right]
$$

where $[\mathrm{AO}]_{0}$ is the initial concentration of $\mathrm{AO}$.

Two different methods can be used to identify the kinetic parameters of Eq. (6). As explained in Appendix A, the most popular method only focuses on the slope at the origin of the depletion curve of AO. But, in this case, it is difficult to access the exact value of each parameter, in particular, the rate constant $\mathrm{k}_{\mathrm{d}}$, which cannot be separated from the initial concentration of hydroperoxides $[\mathrm{POOH}]_{0}$. That is the reason why it was preferred to use a new identification method based on the shape of the depletion curve of $\mathrm{AO}$ at low conversion ratios. According to this new method:

$[A O]=[A O]_{0} \exp \left[-\left(\mathrm{K}+k_{d}[\mathrm{POOH}]_{0}\right) \mathrm{t}+\frac{\mathrm{k}_{\mathrm{d}}^{2}}{2}[\mathrm{POOH}]_{0}[\mathrm{AO}]_{0} \mathrm{t}^{2}\right]$

Eq. (7) can be simplified into Eq. (8) if performing a limited development of the exponential function when the ageing time $t$ tends towards zero:

$[A O]=[A O]_{0}\left[1-\left(\mathrm{K}+k_{d}[\mathrm{POOH}]_{0}\right) \mathrm{t}+\frac{\mathrm{k}_{\mathrm{d}}^{2}}{2}[\mathrm{POOH}]_{0}[\mathrm{AO}]_{0} \mathrm{t}^{2}\right]$

i.e.

$\frac{[A O]-[A O]_{0}}{[A O]_{0}}=-\mathrm{Kt}-k_{d}[\mathrm{POOH}]_{0} t+\frac{\mathrm{k}_{\mathrm{d}}^{2}}{2}[\mathrm{POOH}]_{0}[\mathrm{AO}]_{0} \mathrm{t}^{2}$

Remind that the sulphide is the reactive function of AO, whereas the ester is an inactive group which is present in both the reacted and unreacted AO. It can thus reasonably be assumed that the decrease of the ester concentration observed in Fig. 10 is essentially due to AO physical loss through evaporation, while the decrease of
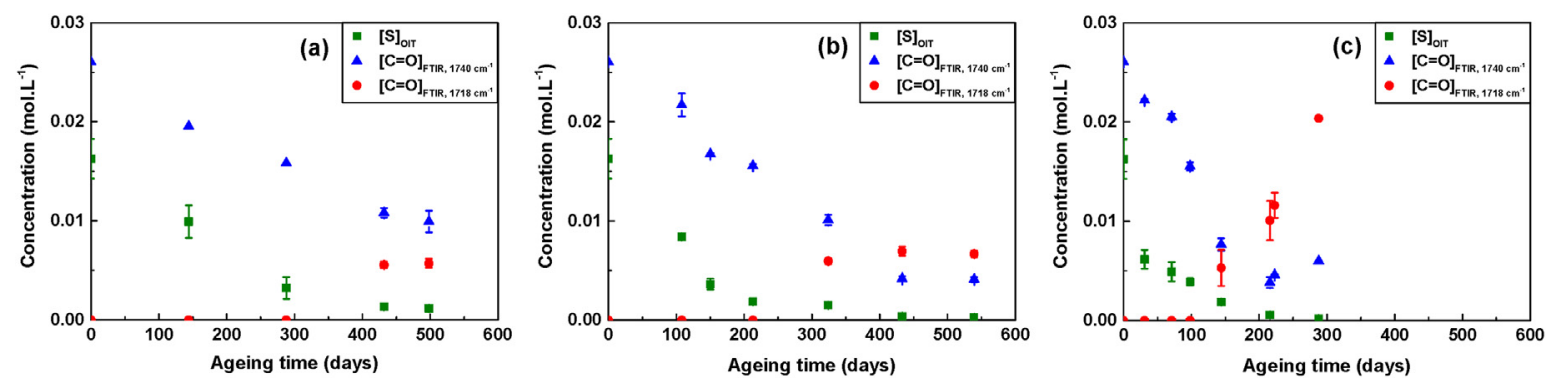

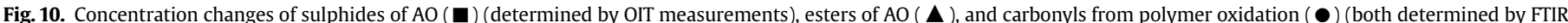

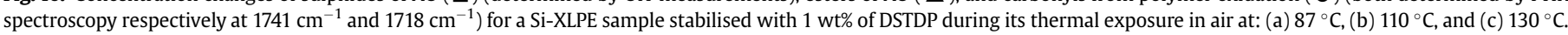


OIT is attributed to both the chemical consumption and physical loss of AO. Fig. 11a shows the kinetic curves of the residual ester concentration for the three temperatures under investigation, of which the slopes at the origin give access to the evaporation constant K. First of all, these values of K were compared with the values of the diffusion coefficient D, calculated using the Arrhenius parameters reported by Moisan for the same AO molecule but in linear PE [12]. It was checked that, at the three temperatures under investigation, the physical loss is indeed controlled by evaporation. According to Calvert and Billingham [27], if the value of the ratio $\phi$ (defined in Eq. (10)) is lower than 0.6, physical loss can be considered to be evaporation-controlled. In contrast, if this ratio is higher than 10, physical loss is diffusion-controlled.

$\phi=\frac{K * e}{D}$

where $\mathrm{K}$ is the evaporation constant (expressed in $\mathrm{s}^{-1}$ ), e the sample thickness $(\mathrm{m})$, and $\mathrm{D}$ the coefficient of AO diffusion $\left(\mathrm{m}^{2} . \mathrm{s}^{-1}\right)$.

The values of K, D and $\phi$ are reported in Table 3 . As shown, the ratio $\phi$ is typically ranged between 0.1 and 0.2 , depending on the temperature under study. However, it should be mentioned that the values of D were obtained from literature data for DSTDP but in linear PE, which might slightly differ in case of a Si-XLPE, due to possible different interactions between $\mathrm{AO}$ molecules and the polymer matrix.

The values of $\mathrm{K}$ were then compared with the few evaporation data reported in the literature for the same AO molecule but in linear PE. In particular, Richaud et al. [16] found an evaporation constant of about $2 \times 10^{-7} \mathrm{~s}^{-1}$ at $110^{\circ} \mathrm{C}$, which is one decade higher than the value determined in the present study. In a first approach, this gap could be explained by a difference in polarity between the two polymer matrices. Indeed, it must not be forgotten that Si-XLPE contains low concentrations of polar functions such as silanols ( $\mathrm{Si}-\mathrm{OH})$, which might strongly interact (via $\mathrm{H}$-bonding) with $\mathrm{AO}$. But, it should also be emphasized that, in their study, Richaud et al. assigned the totality of the AO depletion to physical loss. As it will be seen later, a minor part of this AO depletion is also due to chemical consumption, and the importance of this part can be considerably reinforced if increasing the initial concentration of $\mathrm{POOH}$ (see Eq. (9)). Therefore, it cannot be excluded that the samples studied by Richaud et al. contained an initial concentration of $\mathrm{POOH}$ much higher than our samples.

The same kinetic curves were plotted in Fig. 11b for the concentration of sulphides (i.e. reactive function of AO) estimated by OIT measurements. Indeed, as the sulphide is either physically lost by evaporation or consumed by the chemical reaction (reduction of hydroperoxides), these curves show the global kinetics of AO depletion (physical loss + chemical consumption). Thus, the difference between the results obtained by OIT measurements and
Table 3

Values of the evaporation constant $\mathrm{K}$, diffusion coefficient $\mathrm{D}$, and dimensionless parameter $\phi$ at $87^{\circ} \mathrm{C}, 110^{\circ} \mathrm{C}$, and $130^{\circ} \mathrm{C}$.

\begin{tabular}{llll}
\hline $\mathrm{T}\left({ }^{\circ} \mathrm{C}\right)$ & $\mathrm{K}\left(\mathrm{s}^{-1}\right)$ & $\mathrm{D}\left(\mathrm{m}^{2} . \mathrm{s}^{-1}\right)$ & $\phi$ \\
\hline 87 & $(8.0 \pm 0.7) \times 10^{-9}$ & $2.1 \times 10^{-11}$ & 0.19 \\
110 & $(1.1 \pm 0.1) \times 10^{-8}$ & $7.6 \times 10^{-11}$ & 0.07 \\
130 & $(2.2 \pm 0.4) \times 10^{-8}$ & $2.0 \times 10^{-10}$ & 0.05 \\
\hline
\end{tabular}

FTIR spectroscopy gives access to the kinetic curves of chemical consumption of AO shown in Fig. 12.

As explained in Appendix A, the slope at the origin and the subsequent positive curvature of the kinetic curves of chemical consumption of $\mathrm{AO}$ give access to the second (i.e. $\mathrm{k}_{\mathrm{d}}[\mathrm{POOH}]_{0}$ ) and last terms $\left(1 / 2 \mathrm{k}_{d}^{2}[\mathrm{POOH}]_{0}[\mathrm{AO}]_{0}\right)$ in Eq. (8), respectively. Fig. 8 shows the kinetic modelling of these curves at low conversion ratios by Eq. (9). All these results have been compiled in Table 2.

Knowing the initial concentration of $\mathrm{AO}$, the values of $\mathrm{k}_{\mathrm{d}}$ and $[\mathrm{POOH}]_{0}$ were then easily deduced from the two following quantities: $\mathrm{k}_{\mathrm{d}}[\mathrm{POOH}]_{0}$ and $\mathrm{k}_{\mathrm{d}}^{2}[\mathrm{POOH}]_{0}$. Their respective values are also reported in Table 4.

According to literature, $[\mathrm{POOH}]_{0}$ would typically be ranged between $10^{-5} \mathrm{~mol} \mathrm{~L}^{-1}$ and $10^{-1} \mathrm{~mol} \mathrm{~L}^{-1}$ for linear PE [28-30]. Indeed $[\mathrm{POOH}]_{0}$ depends both on the purity (i.e. presence of structural irregularities, catalytic residues, storage antioxidants, etc.), and preoxidation level of the samples under consideration. Typical values chosen for kinetic modelling are ranged between $9 \times 10^{-3} \mathrm{~mol} \mathrm{~L}^{-1}$ and $5 \times 10^{-2} \mathrm{~mol} \mathrm{~L}^{-1}[31-34]$. Although very close to the detection

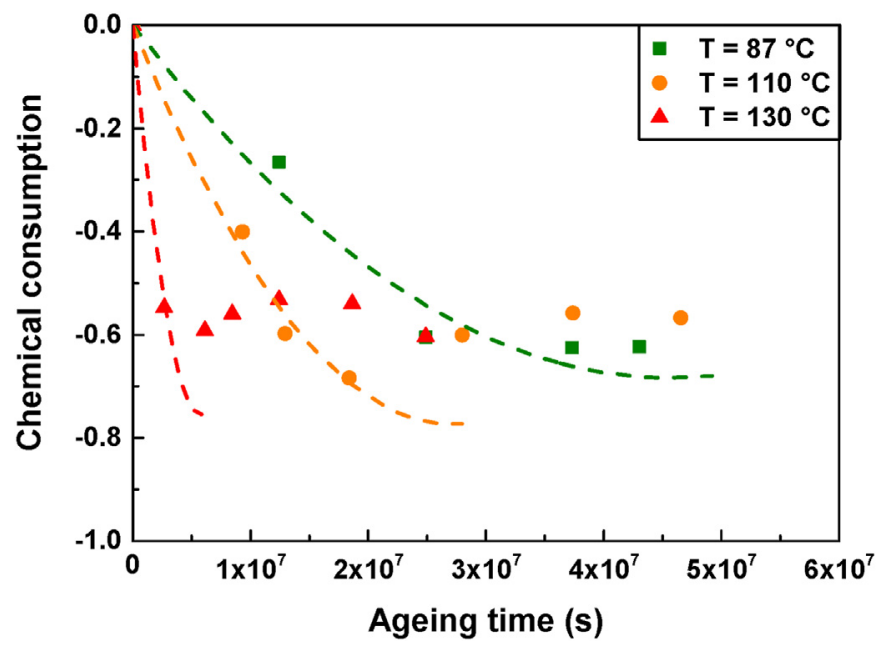

Fig. 12. Kinetic curves in air at $87^{\circ} \mathrm{C}(\boldsymbol{\square}), 110^{\circ} \mathrm{C}(\boldsymbol{\bullet})$, and $130{ }^{\circ} \mathrm{C}(\boldsymbol{\Delta})$ of the chemical consumption of AO in a Si-XLPE sample stabilised with $1 \mathrm{wt} \%$ of DSTDP. The dashed lines follow the kinetic modelling at low conversion ratios with Eq. (9).

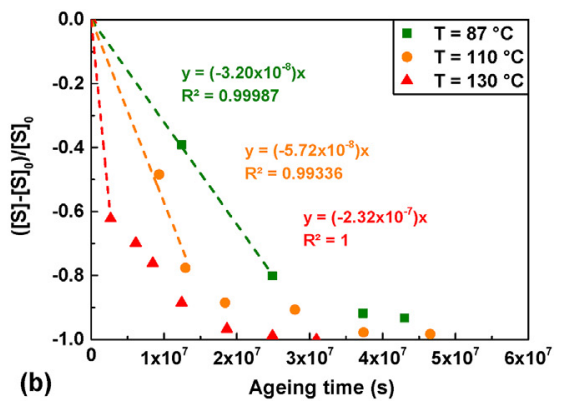

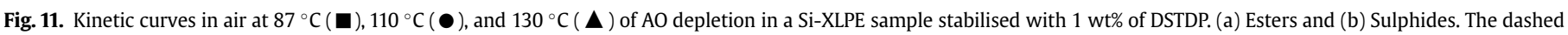
lines give access to the linear equations of the slopes at the origin. 
Table 4

Estimation of the kinetic parameters of the DSTDP depletion in Si-XLPE.

\begin{tabular}{|c|c|c|c|c|c|c|}
\hline & \multicolumn{6}{|c|}{ Method of determination } \\
\hline & \multicolumn{3}{|l|}{ Slope at the origin } & \multirow{2}{*}{$\frac{\text { Curvature }}{\text { OIT - FTIR }}$} & \multicolumn{2}{|l|}{-} \\
\hline & FTIR (Esters) & OIT & OIT - FTIR & & - & \\
\hline$\overline{T\left({ }^{\circ} \mathrm{C}\right)}$ & $\mathbf{K}\left(\mathbf{s}^{-\mathbf{1}}\right)$ & $\overline{\mathbf{K}+\mathbf{k}_{\mathrm{d}}[\mathrm{POOH}]_{\mathbf{0}}\left(\mathbf{s}^{-\mathbf{1}}\right)}$ & 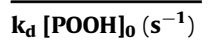 & $\overline{1 / 2 \mathbf{k}_{\mathrm{d}}^{2}[\mathrm{POOH}]_{0}\left(\mathrm{~L} \mathrm{~mol}^{-1} \mathrm{~s}^{-1}\right)}$ & $\mathbf{k}_{\mathrm{d}}\left(\mathbf{L} \cdot \mathrm{mol}^{-1} \cdot \mathrm{s}^{-1}\right)$ & {$[\mathrm{POOH}]_{0}\left(\mathrm{~mol} \mathrm{~L}^{-1}\right)$} \\
\hline 87 & $(8.0 \pm 0.7) \times 10^{-9}$ & $(3.2 \pm 0.1) \times 10^{-8}$ & $(2.4 \pm 0.1) \times 10^{-8}$ & $4.7 \times 10^{-14}$ & $1.6 \times 10^{-6}$ & $1.9 \times 10^{-2}$ \\
\hline 110 & $(1.1 \pm 0.1) \times 10^{-8}$ & $(5.7 \pm 0.3) \times 10^{-8}$ & $(4.5 \pm 0.1) \times 10^{-8}$ & $1.5 \times 10^{-13}$ & $2.6 \times 10^{-6}$ & $2.2 \times 10^{-2}$ \\
\hline 130 & $(2.2 \pm 0.4) \times 10^{-8}$ & $(2.3 \pm 0.1) \times 10^{-7}$ & $(2.0 \pm 0.1) \times 10^{-7}$ & $3.2 \times 10^{-12}$ & $1.2 \times 10^{-5}$ & $2.1 \times 10^{-2}$ \\
\hline
\end{tabular}

threshold of the physico-chemical techniques commonly used for $\mathrm{POOH}$ titration (estimated around $10^{-3} \mathrm{~mol} \mathrm{~L}^{-1}$ for DSC, and $10^{-2} \mathrm{~mol} \mathrm{~L}^{-1}$ for FTIR spectroscopy and iodometry [35]), these values are often confirmed experimentally $[35,36]$. From this rapid literature survey, it can be concluded that the $[\mathrm{POOH}]_{0}$ values determined with Eq. (9) in this study are quite realistic: $(2.0 \pm 0.2) \times 10^{-2} \mathrm{~mol} \mathrm{~L}^{-1}$, that gives a great confidence in the $\mathrm{k}_{\mathrm{d}}$ values deduced therefrom.

The temperature dependences of the evaporation constant $\mathrm{K}$ and the rate constant $k_{d}$ of the chemical consumption of $A O$ in the temperature range under investigation (typically between $87{ }^{\circ} \mathrm{C}$ and $130{ }^{\circ} \mathrm{C}$ ) are shown in Fig. 13.

Although some deviation can be noted (especially for $k_{d}$ ), these two behaviours were modelled in a first approach with the usual Arrhenius law. As a reminder, for a given kinetic parameter $\mathrm{P}$, this law can be expressed as follows:

$P=f_{0} \exp \left(-\frac{E_{a}}{R T}\right)$

where $f_{0}$ is the pre-exponential factor (in the same unit as $P$ ), $E_{a}$ the activation energy $\left(\mathrm{J} \cdot \mathrm{mol}^{-1}\right), \mathrm{R}$ the universal constant of perfect gases $\left(\mathrm{R}=8.314 \mathrm{~J} \mathrm{~mol}^{-1} \mathrm{~K}^{-1}\right)$, and $\mathrm{T}$ the absolute temperature $(\mathrm{K})$.

The general idea was not to describe precisely the temperature dependence of these two parameters, but to determine their Arrhenius parameters in order to compare them with the few data available in the literature. Their corresponding values are compiled in Table 5. The activation energy obtained for $\mathrm{k}_{\mathrm{d}}$ seems to be quite consistent with the value of $44 \mathrm{~kJ} \mathrm{~mol}^{-1}$ reported by Colin et al. [37] for the stabilisation by the sulphide function of a sulphurvulcanized EPDM rubber. Unfortunately, to our knowledge, there is no information on the Arrhenius parameters of $\mathrm{K}$ in the literature.

One reason why the usual Arrhenius law seems not to work very well here could be due to the forgetting of an additional chemical or physical phenomenon in the temperature range under investigation. First of all, it should be recalled that, in this study, the stabilisation reaction was approximated by a single bimolecular step whereas, in the literature, it has been shown that the reaction products of sulphides (e.g. sulfoxides $\mathrm{S}=\mathrm{O}$ ) can also reduce
Table 5

Arrhenius parameters for the DSTDP depletion in Si-XLPE.

\begin{tabular}{lll}
\hline Constants & $\mathrm{E}_{\mathrm{a}}\left(\mathrm{kJ} \cdot \mathrm{mol}^{-1}\right)$ & $\operatorname{Ln}\left(\mathrm{f}_{0}\right)$ \\
\hline $\mathrm{K}$ & $28 \pm 8$ & $-9 \pm 3 \mathrm{~s}^{-1}$ \\
$\mathrm{k}_{\mathrm{d}}$ & $56 \pm 21$ & $5 \pm 7 \mathrm{~L} \mathrm{~mol}^{-1} \mathrm{~s}^{-1}$ \\
\hline
\end{tabular}

hydroperoxides in subsequent stabilisation steps [7,8,37]. It cannot be excluded that these new stabilisation events are differently thermo-activated which could explain the behavioral deviation from the Arrhenius law.

Moreover, it should be pointed out that the melting temperature of Si-XLPE $\left(114{ }^{\circ} \mathrm{C}\right)$ is located almost in the middle of the temperature range under investigation. For an electron-beam irradiation cross-linked polyethylene (XLPE), Langlois et al. [38] observed a jump of about half a decade for the pre-exponential factor around the melting temperature $\left(130{ }^{\circ} \mathrm{C}\right)$ in the Arrhenius diagram of the oxidation induction time. Thus, the increase in molecular mobility when crossing a thermodynamic transition such as the melting, could also explain the behavioral deviation from the Arrhenius law. However, such a discontinuity is relatively subtle and thus, can be hidden by the wider scattering of experimental data in PE compilations [30].

At this stage of investigation, it is certain that too few data have been acquired to accurately assess the extent of the discontinuity and conclude on the validity of the Arrhenius law for describing the experimental results of Fig. 13. Additional experiments should be performed at intermediate temperatures, but also in a much wider temperature range.

\section{Conclusion}

The depletion of a thiodipropionate in a Si-XPLE matrix was investigated in air between 87 and $130{ }^{\circ} \mathrm{C}$ using two complementary physico-chemical techniques: FTIR spectroscopy and DSC under $\mathrm{O}_{2}$. It appeared that this depletion is the result of two contributions: physical loss and chemical consumption (by the stabilisation reactions). Physical loss is by far the main depletion mechanism and it is evaporation-controlled. The corresponding
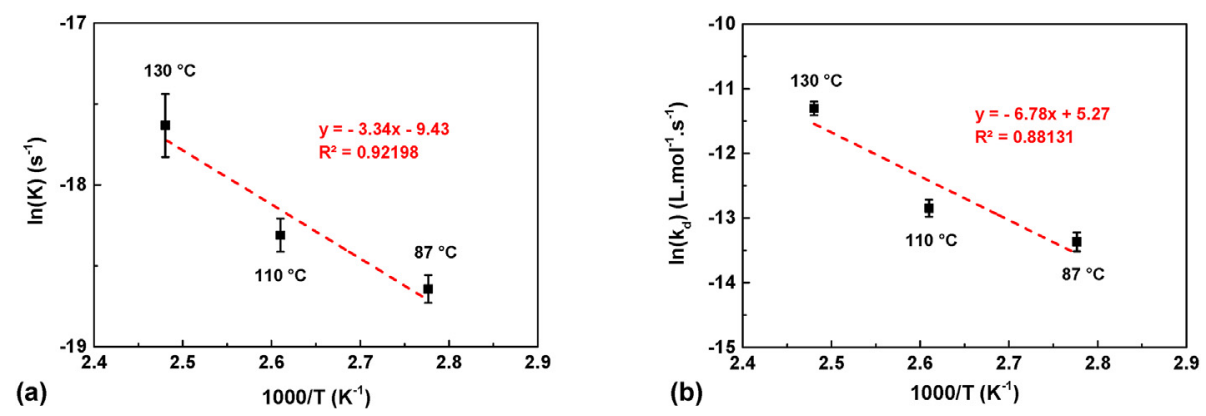

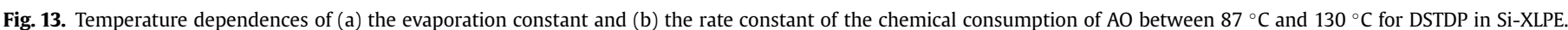


evaporation constant appeared to be one decade lower than in a linear PE presumably due to the higher polarity of the Si-XLPE matrix, thus inducing a reduction in the evaporation rate of AO. However, this hypothesis would imply that the two PE materials contain almost the same initial concentration of $\mathrm{POOH}$, which cannot be demonstrated due to the lack of data for linear PE. Nonetheless, this study highlighted the insufficient amount of data available in the literature on the evaporation of thiodipropionate AO, compared to phenolic AO [39-42].

The small contribution of the chemical reaction was also estimated using a new kinetic equation established at low conversion ratios of the stabilisation reaction. The corresponding rate constant and the initial concentration of $\mathrm{POOH}$ were determined separately from the slope at the origin and the subsequent positive curvature of the depletion curve of AO. The activation energy of this rate constant was found to be relatively close to the few values reported in the literature. However, this value must be considered with caution due to the limited amount of data acquired in this study but also available in the literature, which does not allow checking the validity of Arrhenius law. Furthermore, in a first approach, a single bimolecular reaction was considered for the stabilisation process although it has been shown, in the literature, that the reaction products of sulphides (e.g. sulfoxides $\mathrm{S}=0$ ) can also reduce hydroperoxides in subsequent stabilisation steps $[7,8,37]$. In future work, it would thus be interesting to take into account the additional contribution of sulfoxides $(\mathrm{S}=\mathrm{O})$ in the stabilisation scheme.

As the thermal ageing proceeds, although few AO are still present in the material, some carbonyls coming from polymer oxidation were detected by FTIR spectroscopy. As their concentration is relatively low (typically $\approx 10^{-2} \mathrm{~mol} \mathrm{~L}^{-1}$ ) at the three temperatures under investigation, it can reasonably be considered that the polymer oxidation has not really started yet. Indeed, for pure Si-XLPE, an induction period is clearly observed before the auto-acceleration of oxidation (e.g. about 240 days at $110{ }^{\circ} \mathrm{C}$ ). However, in the case of stabilised Si-XLPE, the duration of the induction period after the total AO depletion is an open question. Will the material behave like a virgin or pre-degraded polymer matrix? Additional analyses after longer ageing durations are in progress to answer this question.

\section{CRediT authorship contribution statement}

Anne Xu: Methodology, Investigation, Conceptualization, Writing - original draft. Sébastien Roland: Validation, Writing review \& editing. Xavier Colin: Validation, Writing - review \& editing, Supervision.

\section{Declaration of competing interest}

The authors declare that they have no known competing financial interests or personal relationships that could have appeared to influence the work reported in this paper.

\section{Acknowledgments}

The TeaM Cables project leading to this application has received funding from the Euratom research and training program 2014-2018 under grant agreement No 755183.

\section{APPENDIX A. Detailed presentation of the Kinetic model and identification of its different parameters}

The AO depletion can be expressed as the contribution of the AO physical loss and chemical consumption. According to Calvert and Billingham [27], in the case of sufficiently thin polymer films, the physical loss is only due to evaporation, of which the corresponding rate is proportional to AO concentration. Concerning the chemical consumption, the main acting mechanism can be summarized by a single bimolecular reaction:

$A O+P O O H \rightarrow$ Inactive products $\left(k_{d}\right)$

The resulting balance equation is:

$\frac{d[A O]}{d t}=-\mathrm{K}[\mathrm{AO}]-k_{d}[\mathrm{AO}][\mathrm{POOH}]$

where $\mathrm{K}$ is the evaporation constant and $\mathrm{k}_{\mathrm{d}}$ the rate constant of the chemical consumption of AO.

Eq. (A.2) can be transformed in a more adequate form to be integrated with respect to time provided that the hydroperoxide concentration does not vary much and remains almost equal to its initial value $[\mathrm{POOH}]_{0}$ (i.e. at low conversion ratios). Thus, it can be written:

$\frac{d[A O]}{[A O]}=-\left(\mathrm{K}+k_{d}[P O O H]\right) d t$

whose integration between 0 and t leads to:

$\ln \left(\frac{[A O]}{[A O]_{0}}\right)=-\left(\mathrm{K}+k_{d}[\mathrm{POOH}]\right) t$

i.e.

$[A O]=[A O]_{0} \exp \left[-\left(\mathrm{K}+k_{d}[\mathrm{POOH}]\right) \mathrm{t}\right]$

where $[\mathrm{AO}]_{0}$ is the initial concentration of $\mathrm{AO}$.

The most popular method [16] for identifying the model parameters focuses on the slope at the origin of the depletion curve of AO. Indeed, Eq. (A.5) can be linearized with a limited development of the exponential function when the ageing time $t$ tends towards zero. It comes:

$[A O]=[A O]_{0}\left[1-\left(\mathrm{K}+k_{d}[\mathrm{POOH}]_{0}\right) \mathrm{t}\right]$

i.e.

$\frac{[A O]-[A O]_{0}}{[A O]_{0}}=-\mathrm{Kt}-k_{d}[\mathrm{POOH}]_{0} t$

As OIT is related to AO concentration, the existence of this initial straight-line can be checked by DSC under a pure $\mathrm{O}_{2}$ flow. However, it is necessary to decouple the contributions of $\mathrm{AO}$ evaporation and chemical consumption to access the respective values of the model parameters.

Remember that the sulphide is the reactive function of $\mathrm{AO}$, whereas the ester is an inactive group which is present in both the reacted and unreacted AO. Thus, the monitoring of the ester depletion by FTIR spectroscopy gives a direct access to the contribution of AO evaporation (first term in Eq. (A.7)) and therefore, to the value of the corresponding evaporation constant K. Remember also that DSTDP contains only one sulphide function, but owns two ester groups. Thus, for esters, the evaporation kinetics must be written:

$\frac{[C=O]-[C=O]_{0}}{[C=O]_{0}}=-2 \mathrm{Kt}$

where $[\mathrm{C}=\mathrm{O}]_{0}$ is the initial concentration of esters.

The contribution of the chemical consumption of AO (second term) can then be simply deduced from Eq. (A.7). However, this first identification method presents as main drawback of not giving 
access to the exact value of the rate constant $k_{d}$ of the chemical consumption. Indeed, this latter cannot be separated from the initial concentration of hydroperoxides $[\mathrm{POOH}]_{0}$.

The new method proposed for accessing all the model parameters is described below. It is not limited to the slope at the origin, but it rather focuses on the general shape of the depletion curve of $\mathrm{AO}$ at low conversion ratios, i.e. typically for: $1 \geq[\mathrm{AO}] /[\mathrm{AO}]_{0}>1 / 2$. To reach this goal, let us assume that the $\mathrm{POOH}$ concentration is a linear function of ageing time, as shown in Fig. (A.1):

$$
\frac{[\mathrm{POOH}]}{[\mathrm{POOH}]_{0}}=1-\frac{\mathrm{t}}{\mathrm{t}_{\mathrm{C}}}
$$

where $t_{C}$ is the characteristic time of the $\mathrm{POOH}$ consumption.

Although it is the simplest hypothesis, it is totally realistic at low conversion ratios. According to Eq. (A.1), the slope of this straightline is given by:

$\frac{d[\mathrm{POOH}]}{d t}=-k_{d}[\mathrm{AO}]_{0}[\mathrm{POOH}]_{0}$

i.e.

$\frac{d[\mathrm{POOH}]}{[\mathrm{POOH}]_{0}}=-k_{d}[\mathrm{AO}]_{0} \mathrm{dt}$

whose integration between 0 and $t$ gives:

$$
\frac{[\mathrm{POOH}]}{[\mathrm{POOH}]_{0}}=1-k_{d}[\mathrm{AO}]_{0} \mathrm{t}
$$

The expression of the characteristic time $t_{C}$ is obtained by equalizing Eq. (A.9) and Eq. (A.12):

$$
t_{C}=\frac{1}{k_{d}[\mathrm{AO}]_{0}}
$$

The introduction of Eq. (A.12) into Eq. (A.2) finally leads to:

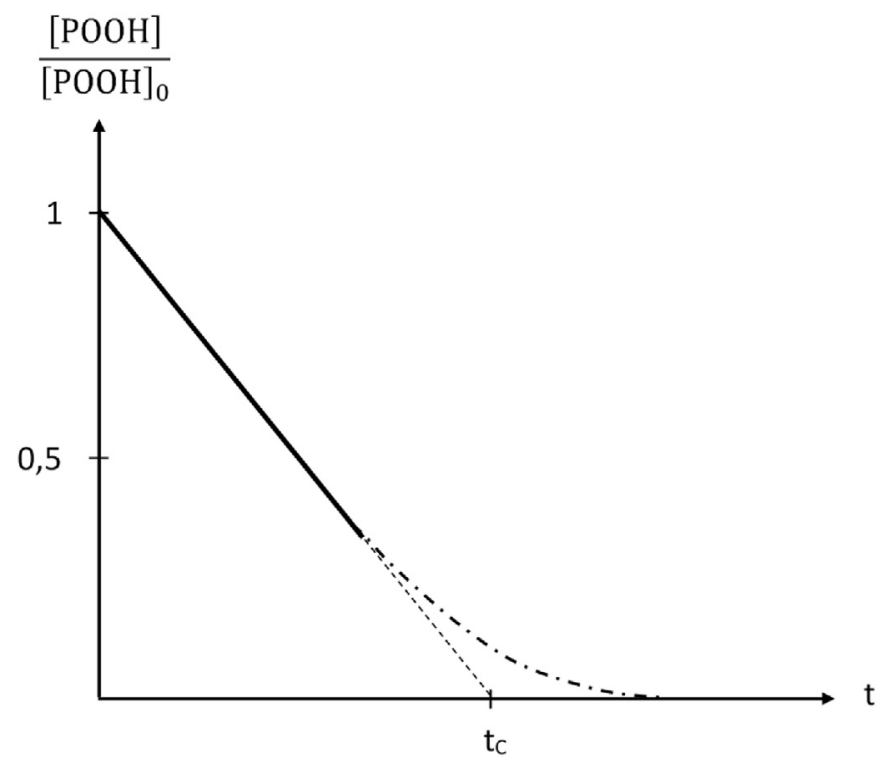

Fig. A.1. Schematization of the changes in $\mathrm{POOH}$ concentration during the stabilisation stage. The initial solid straight-line corresponds to the changes at low conversion ratios described by Eq. (A.9), whereas the subsequent dashed curve shows the deviation to this linear behavior for higher conversion ratios.
$[A O]=[A O]_{0} \exp \left[-\left(\mathrm{K}+k_{d}[\mathrm{POOH}]_{0}\right) \mathrm{t}+\frac{\mathrm{k}_{\mathrm{d}}^{2}}{2}[\mathrm{POOH}]_{0}[\mathrm{AO}]_{0} \mathrm{t}^{2}\right]$

whose subsequent linearization gives:

$[A O]=[A O]_{0}\left[1-\left(\mathrm{K}+k_{d}[\mathrm{POOH}]_{0}\right) \mathrm{t}+\frac{\mathrm{k}_{\mathrm{d}}^{2}}{2}[\mathrm{POOH}]_{0}[\mathrm{AO}]_{0} \mathrm{t}^{2}\right]$

i.e.

$\frac{[A O]-[A O]_{0}}{[A O]_{0}}=-\mathrm{Kt}-k_{d}[\mathrm{POOH}]_{0} t+\frac{\mathrm{k}_{\mathrm{d}}^{2}}{2}[\mathrm{POOH}]_{0}[\mathrm{AO}]_{0} \mathrm{t}^{2}$

As expected, any $\mathrm{POOH}$ consumption induces a slight slowdown in the consumption kinetics of $\mathrm{AO}$ from the low conversion ratios, as shown in Fig. (A.2). This reduction in slope is accounted for the last term in Eq. (A.16), which can be determined by fitting the kinetic curves of chemical consumption of AO. As already explained, these curves can be obtained by removing the contribution of the AO evaporation (determined by monitoring the ester depletion by FTIR spectroscopy) from the AO depletion (determined by measuring OIT by DSC under a pure $\mathrm{O}_{2}$ flow). Knowing the initial concentration of $\mathrm{AO}$, the values of $\mathrm{k}_{\mathrm{d}}$ and $[\mathrm{POOH}]_{0}$ can then be easily deduced from the two following quantities: $\mathrm{k}_{\mathrm{d}}[\mathrm{POOH}]_{0}$ and $\mathrm{k}_{\mathrm{d}}^{2}[\mathrm{POOH}]_{0}$.

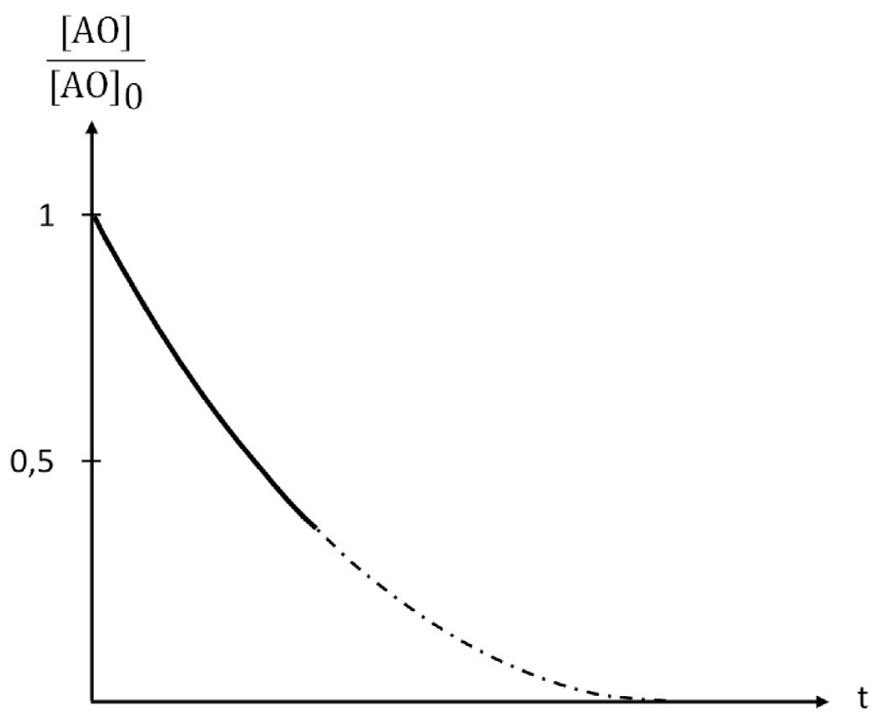

Fig. A.2. Schematization of the changes in AO concentration due to the chemical consumption of AO during the stabilisation stage. The initial solid curve corresponds to the changes at low conversion ratios described by Eq. (A.16), whereas the subsequent dashed curve shows the expected changes at higher conversion ratios.

\section{References}

[1] I. A. E. Agency, Management of life cycle and ageing at nuclear power plants, 2004.

[2] S.V. Suraci, D. Fabiani, A. Xu, S. Roland, X. Colin, Ageing assessment of XLPE LV cables for nuclear applications through physico-chemical and electrical measurements, IEEE, Access 8 (2020) 27086-27096, https://doi.org/10.1109/ ACCESS.2020.2970833. 
[3] J.W. Martin, R.A. Ryntz, J. Chin, R. Dickie, Service life prediction of polymeric materials: global perspectives, springer science \& business media, 2008.

[4] T. Seguchi, K. Tamura, A. Shimada, M. Sugimoto, H. Kudoh, Mechanism of antioxidant interaction on polymer oxidation by thermal and radiation ageing, Radiat. Phys. Chem. 81 (2012) 1747-1751, https://doi.org/10.1016/ j.radphyschem.2012.06.011.

[5] S. Al-Malaika, S. Riasat, C. Lewucha, Reactive antioxidants for peroxide crosslinked polyethylene, Polym. Degrad. Stabil. 145 (2017) 11-24, https:// doi.org/10.1016/j.polymdegradstab.2017.04.013.

[6] S. Al-Malaika, Perspectives in Stabilisation of Polyolefins, in: A.-C. Albertsson (Ed.), Long Term Properties of Polyolefins, Springer Berlin Heidelberg, Berlin, Heidelberg, 2004, pp. 121-150, https://doi.org/10.1007/b13521.

[7] L. Bateman, K.R. Hargrave, E.K. Rideal, Oxidation of organic sulphides. Interaction of cyclohexyl methyl sulphide with hydroperoxides in alcohols, Proceedings of the Royal Society of London, Series A Math. Phys. Sci. 224 (1954) 389-398, https://doi.org/10.1098/rspa.1954.0166.

[8] L. Bateman, K.R. Hargrave, E.K. Rideal, Oxidation of organic sulphides - II Interaction of cyclohexyl methyl sulphide with hydroperoxides in hydrocarbons, Proceedings of the Royal Society of London, Series A Math. Phys. Sci. 224 (1954) 399-411, https://doi.org/10.1098/rspa.1954.0167.

[9] H. Zweifel, R.D. Maier, M. Schiller, Plastics additives handbook, 2009, p. 1258.

[10] E. Richaud, J. Verdu, Vieillissement chimique des polymères Physicochimie de la stabilisation, Techniques de l'ingénieur Propriétés Générales Des Plastiques, base documentaire : TIB152DUO (2012). https://www.techniques-ingenieur $\mathrm{fr} /$ base-documentaire/materiaux-th11/proprietes-generales-des-plastiques42152210/vieillissement-chimique-des-polymeres-am3153/.

[11] H. Zweifel, Stabilization of polymeric materials, springer science \& business media, 2012.

[12] J.Y. Moisan, Diffusion des additifs du polyethylene-I: influence de la nature du diffusant, Eur. Polym. J. 16 (1980) 979-987, https://doi.org/10.1016/00143057(80)90180-9.

[13] J.Y. Moisan, R. Lever, Diffusion des additifs du polyethylene- $-\mathrm{V}$ : influence sur le vieillissement du polymere, Eur. Polym. J. 18 (1982) 407-411, https:// doi.org/10.1016/0014-3057(82)90177-X.

[14] J.Y. Moisan, Solubilite des additifs du polyethylene: methodes et resultats, Eur. Polym. J. 19 (1983) 1127-1130, https://doi.org/10.1016/0014-3057(83) 90007-1.

[15] H.E. Bair, Exudation of an antioxidant additive from thin polyethylene films, Polym. Eng. Sci. 13 (1973) 435-439, https://doi.org/10.1002/pen.760130607.

[16] E. Richaud, C. Monchy-Leroy, X. Colin, L. Audouin, J. Verdu, Kinetic modelling of stabilization coupled with stabilizer loss by evaporation. Case of dithioester stabilized polyethylene, Polym. Degrad. Stabil. 94 (2009) 2004-2014, https:// doi.org/10.1016/j.polymdegradstab.2009.07.017.

[17] Team Cables, D2.2: Specifications of Tests - Accelerated Ageing Protocol, Test Strategy, 2018.

[18] A. Xu, S. Roland, X. Colin, Physico-chemical characterization of the blooming of Irganox 1076® antioxidant onto the surface of a silane-crosslinked polyethylene, Polym. Degrad. Stabil. 171 (2020), 109046, https://doi.org/10.1016 j.polymdegradstab.2019.109046.

[19] A. Wypych, G. Wypych, Databook of Antioxidants, Elsevier, 2020.

20] S. Bensason, J. Minick, A. Moet, S. Chum, A. Hiltner, E. Baer, Classification of homogeneous ethylene-octene copolymers based on comonomer content, J. Polym. Sci. B Polym. Phys. 34 (1998) 1301-1315, https://doi.org/10.1002/ (SICI)1099-0488(199605)34:7<1301::AID-POLB12>3.0.CO;2-E.

[21] K. Sirisinha, S. Chimdist, Comparison of techniques for determining crosslinking in silane-water crosslinked materials, Polym. Test. 25 (2006) 518-526, https://doi.org/10.1016/j.polymertesting.2006.01.015.

[22] D20 Committee, Test method for oxidative-induction time of polyolefins by differential scanning calorimetry. ASTM International. n.d. https://doi.org/10 1520/D3895-19.

[23] J. Posplisil, Z. Horak, J. Pilar, N.C. Billingham, H. Zweifel, S. Nespurek, Influence of testing conditions on the performance and durability of polymer stabilisers in thermal oxidation, Polym. Degrad. Stabil. 82 (2003) 145-162, https:// doi.org/10.1016/S0141-3910(03)00210-6.

[24] E. Kramer, J. Koppelmann, Thermo-oxidative degradation of polyolefins observed by isothermal long-term DTA, Polym. Eng. Sci. 27 (1987) 945-954, https://doi.org/10.1002/pen.760271305.

[25] J.R. Pauquet, R.V. Todesco, W.O. Drake, Limitations and applications of oxidative induction time (OIT) to quality control of polyolefins, 42nd International Wire \& Cable Symposium, 1993, pp. 77-86.

[26] F.M. Rugg, J.J. Smith, R.C. Bacon, Infrared spectrophotometric studies on polyethylene. II. Oxidation, J. Polym. Sci. 13 (1954) 535-547, https://doi.org/ 10.1002/pol.1954.120137202.

[27] P.D. Calvert, N.C. Billingham, Loss of additives from polymers: a theoretical model,, J. Appl. Polym. Sci. 24 (1979) 357-370, https://doi.org/10.1002/ app.1979.070240205

[28] E. Richaud, X. Colin, B. Fayolle, L. Audouin, J. Verdu, Induction period in the low-temperature thermal oxidation of saturated hydrocarbons: example of polyethylene, Int. J. Chem. Kinet. 40 (2008) 769-777, https://doi.org/10.1002/ kin.20347.

[29] X. Colin, B. Fayolle, L. Audouin, J. Verdu, About a quasi-universal character of unstabilised polyethylene thermal oxidation kinetics, Polym. Degrad. Stabil. 80 (2003) 67-74, https://doi.org/10.1016/S0141-3910(02)00384-1.

[30] N. Khelidj, X. Colin, L. Audouin, J. Verdu, C. Monchy-Leroy, V. Prunier, Oxidation of polyethylene under irradiation at low temperature and low dose rate. Part II. Low temperature thermal oxidation, Polym. Degrad. Stabil. 91 (2006) 1598-1605, https://doi.org/10.1016/j.polymdegradstab.2005.09.012.

[31] E. Richaud, L. Audouin, X. Colin, B. Fayolle, J. Verdu, Rôle des hydroperoxydes dans le vieillissement oxydant des matériaux polymères, Mater. Technol. 96 (2008) 27-42, https://doi.org/10.1051/mattech:2008022.

[32] X. Colin, L. Audouin, J. Verdu, Determination of thermal oxidation rate constants by an inverse method. Application to polyethylene, Polym. Degrad. Stabil. $86 \quad$ (2004) 309-321, https://doi.org/10.1016/ j.polymdegradstab.2004.04.022.

[33] X. Colin, L. Audouin, J. Verdu, M. Rozental-Evesque, B. Rabaud, F. Martin, F. Bourgine, Aging of polyethylene pipes transporting drinking water disinfected by chlorine dioxide. I. Chemical aspects, Polym. Eng. Sci. 49 (2009) 1429-1437, https://doi.org/10.1002/pen.21258.

[34] X. Colin, L. Audouin, J. Verdu, M. Rozental-Evesque, B. Rabaud, F. Martin, F. Bourgine, Aging of polyethylene pipes transporting drinking water disinfected by chlorine dioxide. Part II-lifetime prediction, Polym. Eng. Sci. 49 (2009) 1642-1652, https://doi.org/10.1002/pen.21387.

[35] M.D. Cruz, L.V. Schoors, K. Benzarti, X. Colin, Thermo-oxidative degradation of additive free polyethylene. Part I. Analysis of chemical modifications at molecular and macromolecular scales, J. Appl. Polym. Sci. 133 (2016), https:// doi.org/10.1002/app.43287.

[36] J. Huang, W. Minne, R. Drozdzak, G. Recher, P.Y. Le Gac, E. Richaud, Thermal oxidation of poly(dicyclopentadiene) - decomposition of hydroperoxides, Poly. Degrad. Stabil. 174 (2020), 109102, https://doi.org/10.1016/ j.polymdegradstab.2020.109102.

[37] X. Colin, M.B. Hassine, M. Nait-Abelaziz, Chemo-mechanical model for predicting the lifetime of EPDM rubbers, Rubber Chem. Technol. 92 (2019) 722-748, https://doi.org/10.5254/rct.19.81469.

[38] V. Langlois, L. Audouin, J. Verdu, P. Courtois, Thermooxidative aging of crosslinked linear polyethylene: stabilizer consumption and lifetime prediction, Polym. Degrad. Stabil. 40 (1993) 399-409, https://doi.org/10.1016/01413910(93)90150-H.

[39] S. Matsumoto, Behavior of antioxidant in polyethylene, Journal of Polymer Science Part A, Polym. Chem. 21 (1983) 557-564, https://doi.org/10.1002/ pol.1983.170210222.

[40] M. Seker, S. Tercan, Kinetics of polyphenol losses and antioxidant activity of extracts from olive cake during evaporation, Int. J. Food Prop. 15 (2012) 438-449, https://doi.org/10.1080/10942912.2010.487968.

[41] L. Campanella, A. Nuccilli, M. Tomassetti, S. Vecchio, Biosensor analysis for the kinetic study of polyphenols deterioration during the forced thermal oxidation of extra-virgin olive oil, Talanta 74 (2008) 1287-1298, https://doi.org/ 10.1016/j.talanta.2007.08.036.

[42] X. Colin, J. Verdu, B. Rabaud, Stabilizer thickness profiles in polyethylene pipes transporting drinking water disinfected by bleach, Polym. Eng. Sci. 51 (2011) 1541-1549, https://doi.org/10.1002/pen.21902. 